\title{
Neural patterning: The role of Nkx genes in the ventral spinal cord
}

\author{
Andrew P. McMahon ${ }^{1}$ \\ Department of Molecular and Cellular Biology, The Biolabs, Harvard University, Cambridge, Massachusetts 02138, USA
}

The mammalian nervous system is extremely complex, consisting of many thousands of distinct neuronal cell types, any one of which may require multiple cell interactions to generate a functional circuit. The elaboration of this circuitry is dependent in no small part on the logic of the developmental program that ensures that appropriate cell types are generated at specific positions in the brain or spinal cord, in the correct numbers, and at the correct stage of development. Given the relative simplicity of the spinal cord circuitry, it has become the model of choice for addressing these problems.

Only 7 years ago our understanding of neural development in the spinal cord was rudimentary. A number of studies had highlighted the importance of regional organizing centers, both outside and within the developing neural plate and neural tube, in generating the early pattern (for review, see Edlund and Jessell 1999). However, none of these putative inductive signals had been identified. Consequently, there was no molecular framework within which to construct a plausible model for generating cell type diversity in the developing spinal cord. As we fast-forward to the present, the situation is dramatically different.

The first major inroad came with the discovery of Sonic hedgehog (Shh; Echelard et al. 1993; Krauss et al. 1993; Riddle et al. 1993; Roelink et al. 1994). Shh encodes a ventralizing signal produced by two ventral midline structures, the notochord, which underlies the ventral neural plate, and the floor plate, a specialized population of glial cells at the ventral midline of the developing hindbrain and spinal cord. It is now clear that Shh is both necessary and sufficient for the induction of the floor plate (notwithstanding evidence that, in some organisms, cell lineage and not simply induction may account for some floor plate cell fates; Le Douarin and Halpern 2000; Placzek et al. 2000), motor neurons, and a number of distinct ventral interneurons (for review, see Jessell 2000). Moreover, there is strong evidence that the concentration of Shh dictates the position where distinct ventral cell identities arise; developmentally naïve inter-

${ }^{1}$ E-MAIL amcmahon@mcb.harvard.edu; FAX (617) 496-3763. Article and publication are at www.genesdev.org/cgi/doi/10.1101/ gad. 840800 . mediate neural plate explants respond to small incremental changes in the external concentration of Shh protein to give rise to distinct cell fates (Ericson et al. 1997). At least five distinct cell identities are thought to arise as a primary response to Shh signaling (Fig. 1). These are (from ventral to dorsal) floor plate, V3 interneurons, motor neurons, V2 interneurons, and V1 interneurons. This general model leads to three central questions. How is the Shh concentration gradient generated? How is this gradient translated into distinct transcriptional responses? And finally, what are the transcriptional regulators that lock in a particular neuronal or glial fate?

Little progress has been made in addressing the first question. Shh undergoes a unique processing event that appends a cholesterol moiety to the carboxy-terminal amino acid of the amino-terminal signaling moiety (Porter et al. 1996). As a result, the modified protein appears to be retained at the cell surface. However, antibody blocking experiments demonstrate that at least some protein does travel beyond Shh-expressing cells and into the ventral field of Shh-responsive cells (Ericson et al. 1996). This conclusion is also supported indirectly by the observed transcriptional up-regulation of the gene encoding a multipass membrane protein, Patched-1 (Goodrich et al. 1996; Marigo and Tabin 1996), which serves as a general Hedgehog $(\mathrm{Hh})$ receptor and is a general transcriptional target of the pathway.

Many lines of evidence indicate that transduction of an Hh signal modulates the activity and/or expression of the Gli/Ci family of zinc-finger DNA binding proteins (for review, see Ruiz i Altaba 1999). In the mouse, which has three Gli family members, Gli2 loss-of-function mutants have a complete absence of floor plate development, consistent with a specific role for Gli2 in mediating the role of Shh in floor plate induction (Ding et al. 1998; Matise et al. 1998). The simplest model would then indicate that other Gli members may direct the development of other ventral cell identities, either uniquely or in combination. However, this does not appear to be the case, at least as far as current publications on the analysis of combinatorial mutants in Gli genes indicate. If this result holds, this leaves open two opposing interpretations. In the first, Shh plays a less direct role in inducing all ventral cell fates, that is, there may be secondary signals. Evidence has been presented for 
A

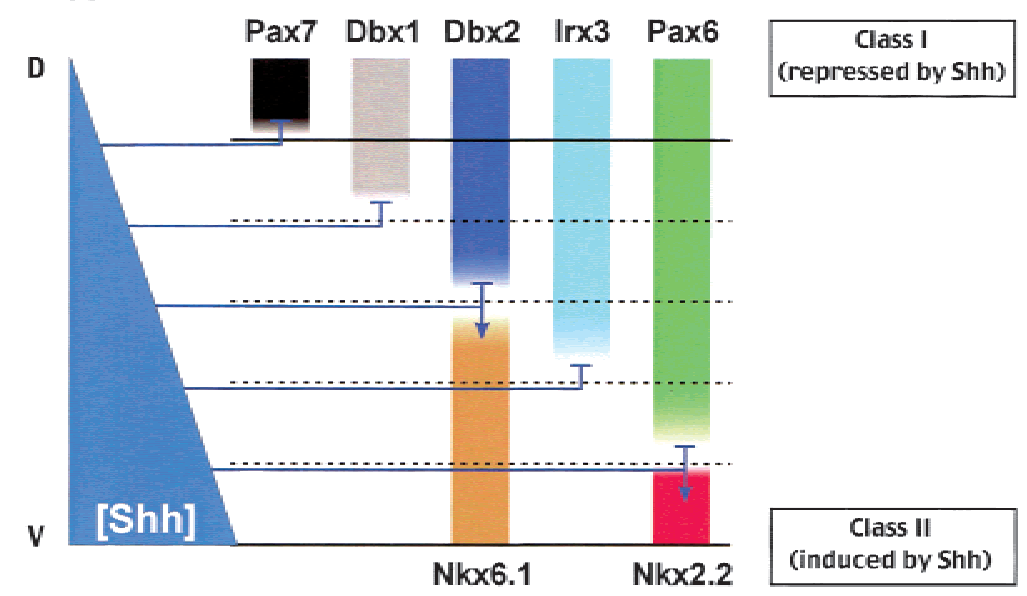

B

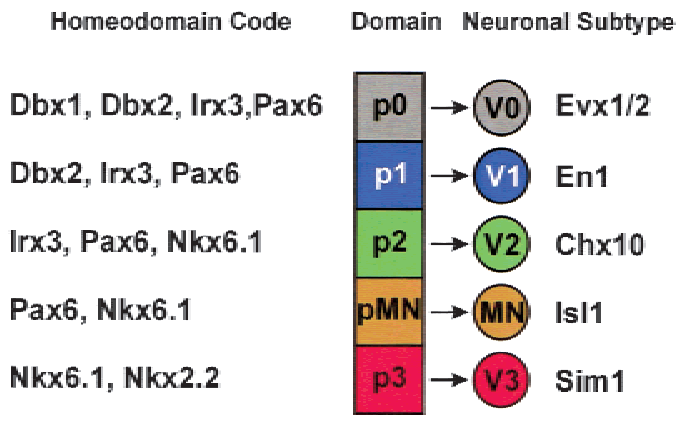

Figure 1. A model for the role of graded Sonic hedgehog (Shh) signaling in the establishment of ventral cell fates in the vertebrate spinal cord. (A) Graded Shh signaling establishes the ventral expression domains of a number of homeodomain transcriptional regulators in neural progenitor populations. Distinct boundaries are established on the basis of Shh-mediated repression (class I) or induction (class II) at different concentration thresholds. (B) The relationship between a given homeodomain code established in response to Shh signaling and the formation of specific neuronal subtypes. D, dorsal; V, ventral. (Figure kindly provided by Tom Jessell).

retinoid signaling in the ventral neural tube, but this is at later stages in the induction of distinct classes of motor neurons (Sockanathan and Jessell 1998). The second interpretation is that not all Shh signaling is mediated directly by Gli factors. Indeed, evidence implicates CoupTFII as a possible immediate target of Shh's action in motor neurons (Krishnan et al. 1997).

Clearly the most direct means of determining which cells require a direct Shh input is to identify target genes whose expression is regulated by Shh. It is then possible, at least in principle, to define the regulatory region responsible for Shh-dependent transcription and to determine the nature of regulatory interactions occurring at these sites and their relationship to the Shh signal transduction pathway.

Work done principally in the Jessell laboratory has defined a series of partially overlapping homeodomain-containing proteins expressed in neuroprogenitor cells in the ventricular zone of the neural tube (Fig. 1). In an attractive model, Jessell and colleagues have suggested that expression of a given set of homeodomain proteins constitutes a neural code that eventually leads to the production of a specific neuronal subtype (Fig. 1; Briscoe et al. 2000). These neuronal subtypes can, in turn, be identified by a distinct pattern of transcriptional regulators. Returning to the neural progenitors, the expression of a specific code in a given position in the ventral ventricular zone is suggested to depend on the differential sensitivity of these homeodomain genes to the repressive or activating effects of Shh; class I genes are repressed, and class II genes are activated by different threshold concentrations of Shh in vitro (Briscoe et al. 2000). Furthermore, there is good agreement between these thresholds and the position at which a given gene is expressed in ventral neural precursors in the presumptive spinal cord. However, whether any of these genes are direct targets re- mains to be determined. To summarize the prevailing Jessell model, a Shh concentration gradient generates a cellular code of homeodomain transcriptional effectors activated at a precise position along the $\mathrm{D}-\mathrm{V}$ neural axis. In turn, this code determines which postmitotic neuronal type is generated from a specific progenitor population.

This model is also appealing because of its inherent simplicity and its testability. One key prediction is a strict precursor-product relationship between cells expressing a particular homeodomain protein code and the postmitotic cell type (motor neuron or interneuron) that forms from these cells. The most rigorous test of this prediction would entail cell lineage studies. The combination of Cre recombinase and ubiquitous reporters activated by Cre-mediated recombination will allow the fates of all cells expressing a particular homeodomain gene to be mapped in the future. Although this is an important issue, a strict lineage relationship provides no actual test of the importance of a given homeodomain code in any specific cell fate choice. Here, gain-of-function and loss-of-function mutants, resulting from ectopic expression or mutation of the genes encoding specific factors, have provided important insights. Each approach, however, has an inherent weakness. Ectopic expression requires that one divert the developmental fate of a specific cell type in a predictable fashion by altering, in this case, the code of homeodomain genes that are expressed in that cell. Of course, any one factor may not be sufficient to do this, even if it can be shown by lossof-function studies to be necessary. Conversely, genetic redundancy between overlapping expression domains of highly related genes has been the bane of loss-of-function studies. However, when the application of these distinct approaches actually yields complementary results, there is a real satisfaction that the model may be true. 
Much of the work to date on the role of homeodomain protein codes as an output for Shh signaling in the specification of ventral cell identities has focused on a family of transcription factors, the $N k x$ genes. One of these, $N k x 2.2$, is expressed in a small population of neural progenitors immediately adjacent to the floor plate that are thought to give rise to V3 interneurons (Fig. 1). A causal role for $N k \times 2.2$ in V3 interneuron specification comes from loss-of-function studies in which V3 interneuron precursors adopt the fate of the nextmost dorsal progenitor cell population generating ectopic motor neurons (Fig. 1; Briscoe et al. 1999).

Most recently, attention has focused on a second family member, Nkx6.1. Unlike Nkx2.2, Nkx6.1 shows broader expression in the spinal cord occupying approximately one-third of the D-V axis of the neural tube at 9.5 days post coitum (dpc). Based on comparative expression analyses of marker genes, but not strict cell lineage studies, Jessell and colleagues suggest that Nkx6.1-expressing cells give rise to three neuronal subtypes: V3 interneurons, motor neurons, and V2 interneurons, from ventral to dorsal, respectively (Briscoe et al. 2000). However, the Jessell combinatorial code model predicts that the unique cell type generated is dictated by other factors acting in concert with $N k \times 6.1 . N k \times 6.1$ is a class II gene; that is, it is activated by Shh signaling (Briscoe et al. 2000). Whether it is a direct target of Shh remains to be determined. As its concentration threshold appears to be low, it is initially activated broadly within the ventral neural tube. Recent work indicates that Shh dependence is likely to be relatively brief. After the specific domains of homeodomain gene expression are established by Shh signaling, mutual repression among the homeodomain factors themselves appears to consolidate and maintain expression domains in the rapidly growing neural tube (Briscoe et al. 2000). For example, ectopic expression studies in the chick indicate that $N k x 6.1$ is repressed by another homeodomain protein, Dbx2, while ventral $D b x 2$ expression is itself prevented by $\mathrm{Nkx} 6.1$ (Briscoe et al. 2000).

What role does Nkx6.1 play in the specification of ventral cell identities and by what mechanisms? A revealing set of experiments from the Rubenstein and Jessell laboratories recently published in Genes \& Development (Sander et al. 2000) provides some clues and at the same time raises a number of questions about the patterning mechanism.

The basic observation is that in the absence of $N k \times 6.1$ there appears to be a specific loss of two of the three neuroprogenitor populations associated with $N k x 6.1$ expression, V2 interneurons and motor neurons. Coupled with this is a ventral-ward expansion of V1 interneurons, the cell type formed by $D b x 2$-expressing neural progenitors normally located immediately dorsal to the Nkx6.1 domain. Accompanying what appears to be a classic cell fate switching is the ectopic activation of $D b \times 2$ in more ventral neural progenitor populations as predicted from the chick experiments discussed above. $D b x 2$ in V2 progenitors lacking $N k x 6.1$ is predicted to change a V2 code to that of V1 progenitors (Fig. 1). It is argued that the effects are likely to be independent of Shh itself, as Shh appears to be expressed normally in the floor plate. Although this is probably correct, it would clearly be better to know about Shh in the region where these decisions are taking place. Visualizing Shh itself outside of the floor plate has been a general problem in the field. A normal pattern of Patched-1 up-regulation would go some way to addressing whether signaling is indeed nor$\mathrm{mal}$ in the regions where cell fate switching is observed.

Where things get murkier is in the detail, most importantly in the influence of rostral-caudal position and in the kinetics of the observed events. Whereas a strong suppression of motor neuron development is observed at rostral positions in the developing spinal cord, only a modest reduction is observed more caudally. Since the model thus far sees the spinal cord as a homogeneous structure, what accounts for this difference? Furthermore, whereas there is no selectivity in the loss of specific subpopulations of motor neurons in the spinal cord, there is in the hindbrain where Nkx6.1 is also broadly expressed. Here, visceral motor neurons are present but somatic motor neurons are lost. A likely explanation, although it remains to be tested, is the overlapping role of $N k x 2.2$. At spinal cord levels $N k \times 2.2$ is expressed in V3 interneurons, and these remain in $N k x 6.1$ mutants. However, in the hindbrain, $N k x 2.2$ and $N k x 2.9$, a highly related family member, are coexpressed in visceral motor neurons. Consequently, redundancy among Nkx2.2, $N k x 2.9$, and $N k \times 6.1$ could account for the presence of V3 interneurons in the spinal cord and visceral motor neurons in the hindbrain of Nkx6.1 mutants. However, the redundancy argument does not agree well with the apparent ectopic expression of $D b \times 2$ in the mutant, which seems to be specific at early stages $(10.5 \mathrm{dpc})$ for the Nkx2.2 domain, although double labeling with antibodies recognizing $N k \times 2.2$ and $D b x 2$ is not presented. If true, $N k x 2.2$ is not sufficient to repress $D b \times 2$ in the absence of $N k x 6.1$. Further, it is not until $12.5 \mathrm{dpc}$ that $\mathrm{Dbx} 2$ is now expressed ectopically in V2 progenitors. Does this timing fit with the complete absence of Chx10-expressing V2 interneurons and their apparent respecification to a V1 interneuron fate as well as the almost complete suppression of rostral motor neuron fates in the spinal cord? These are interesting issues that will require a more detailed analysis of the early stages of development. With respect to the motor neuron fate itself, it is interesting to ask what is actually required for motor neuron specification. Perhaps repression of $D b x 2$, which is normally mediated by Nkx6.1, is the key. In this regard it will be interesting to examine the phenotype of $D b x 2 / N k x 6.1$ compound mutants to determine whether there is a rescue of motor neuron fates. However, there is a possible complication in that Gsh1 and Gsh2, two distinct homeodomain protein-encoding genes, are ectopically expressed ventrally in Nkx6.1 mutants with a pattern very similar to that of $D b \times 2$ (Sander et al. 2000). Gsh1/2 are normally expressed in the dorsal half of the neural tube at some distance from the dorsal boundary of $N k \times 6.1$ expression, hence their activation comes as something of a surprise. However, it appears 
that they are general targets of $N k x 6.1$ repression as they are also ectopically activated outside of the neural tube where $N k x 6.1$ is normally expressed (Sander et al. 2000)

In summary, accumulating evidence indicates that cell type diversity in both the dorsal (for review, see Lee and Jessell 1999) and ventral central nervous system is dependent on the initial action of qualitatively distinct signals acting in a concentration-dependent fashion to establish autonomous subdomains of homeodomain protein activity along the $\mathrm{D}-\mathrm{V}$ axis of the neural tube. The establishment of this homeodomain code in neural progenitors determines the identity of differentiating neural cells. Determining how exactly a Shh gradient is translated into a specific code of homeodomain proteins and how this code results in neural progenitors giving rise to a specific type of neuron will require further molecular and cellular dissection of these processes. In addition, these events have to be carefully orchestrated and integrated with cell proliferation in the rapidly growing neural tube. Finally, there is accumulating evidence that cells in a given progenitor population may give rise to distinct cell fates at different times (see Jessell 2000). How temporal switching of cell fates might be regulated is unclear. However, if the rapid progress of the last few years is a reasonable measure, we can expect more revealing insights into the mechanisms that pattern the vertebrate spinal cord in the near future.

\section{Acknowledgments}

I thank Tom Jessell for the figure. Owing to space constraints, the citations are selective and I apologize to anyone whom this upsets. Work in my laboratory is supported by grants from the NIH.

\section{References}

Briscoe, J., Sussel, L., Serup, D., Hartigan-O'Conner, D., Jessell, T.M., Rubenstein, J.L.R., and Ericson, J. 1999. Homeobox gene $N k x 2.2$ and specification of neuronal identity by graded Sonic hedgehog signaling. Nature 398: 622-627.

Briscoe, J., Pierani, A., Jessell, T.M., and Ericson, J.A. 2000. A homeodomain protein code specifies progenitor cell identity and neuronal fate in the ventral neural tube. Cell 101: 435-445.

Ding, Q., Motoyama, J., Gasca, S., Mo, R., Sasaki, H., Rossant, J., and Hui, C.C. 1998. Diminished sonic hedgehog signaling and lack of floor plate differentiation in Gli2 mutant mice. Development 125: 2533-2543.

Echelard, Y., Epstein, D.J., St.-Jacques, B., Shen, L., Mohler, J., McMahon, J.A., and McMahon, A.P. 1993. Sonic hedgehog, a member of a family of putative signaling molecules, is implicated in the regulation of CNS polarity. Cell 75: 1417-1430.

Edlund, T. and Jessell, T.M. 1999. Progression from extrinsic to intrinsic signaling in cell fate specification: A view from the nervous system. Cell 96: 211-224.

Ericson, J., Morton, S., Kawakami, A., Roelink, H., and Jessell, T.M. 1996. Two critical periods of Sonic hedgehog signaling required for the specification of motor neuron identity. Cell 87: 661-673.

Ericson, J., Rashbass, P., Schedl, A., Brenner-Morton, S., Kawakami, A., van Heyningen, V., Jessell, T.M., and Briscoe, J. 1997. Pax6 controls progenitor cell identity and neuronal fate in response to graded Shh signaling. Cell 90: 169-180.

Goodrich, L.V., Johnson, R.L., Milenkovic, L., McMahon, J.A., and Scott, M.P. 1996. Conservation of the hedgehog/patched signaling pathway from flies to mice: Induction of a mouse patched gene by hedgehog. Genes \& Dev. 10: 301-312.

Jessell, T.M. 2000. Cell patterning in the ventral spinal cord: Inductive signals and transcription codes. Nat. Genet. (in press).

Krauss, S., Concordet, J.P., and Ingham, P.W. 1993. A functionally conserved homologue of the Drosphila segment polarity gene $h h$ is expressed in tissues with polarizing activity in zebrafish embryos. Cell 75: 1431-1444.

Krishnan, V., Pereira, F.A., Qiu, Y., Chen, C.H., Beachy, P.A., Tsai, S.Y., and Tsai, M.J. 1997. Mediation of Sonic hedgehoginduced expression of COUP_TFII by a protein phosphatase. Science 278: 1947-1950.

Le Douarin, N.M. and Halpern, M.E. 2000. Origin and specification of the neural tube floor plate: Insights from the chick and zebrafish. Curr. Opin. Neurobiol. 10: 23-30.

Lee, K.J. and Jessell, T.M. 1999. The specification of dorsal cell fates in the vertebrate central nervous system. Annu. Rev. Neurosci. 22: 261-294.

Marigo, V. and Tabin, C.J. 1996. Regulation of patched by Sonic hedgehog in the developing neural tube. Proc. Natl. Acad. Sci. 93: 9346-9351.

Matise, M.P., Epstein, D.J., Park, H.L., Platt, K.A., and Joyner, A.L. 1998. Gli2 is required for induction of floor plate and adjacent cells, but not most ventral neurons in the mouse central nervous system. Development 125: 2759-2770.

Placzek, M., Dodd, J., and Jessell, T.M. 2000. The case for floor plate induction by the notochord. Curr. Opin. Neurobiol. 10: $15-22$.

Porter, J.A., Young, K.E., and Beachy, P.A. 1996. Cholesterol modification of hedgehog signaling proteins in animal development. Science 274: 255-259.

Riddle, R.D., Johnson, R.L., Laufer, E., and Tabin, C. 1993. Sonic hedgehog mediates the polarizing activity of the ZPA. Cell 75: 1401-1416.

Roelink, H., Augsburger, A., Heemskerk, J., Korzh, V., Norlin, S., Ruiz i Altaba, A., Tanabe, Y., Placzek, M., Edlund, T., Jessell, T.M., et al. 1994. Floor plate and motor neuron induction by vhh-1, a vertebrate homologue of hedgehog expressed by the notochord. Cell 76: 761-775.

Ruiz i Altaba, A. 1999. The works of GLI and the power of hedgehog. Nat. Cell Biol. 1: E147-E148.

Sander, M., Paydar, S., Ericson, J., Brisco, J., German, M., Jessell, T.M., and Rubenstein, J. 2000. Ventral neural patterning by Nkx homeobox genes: Nkx6.1 controls somatic motor neuron and ventral interneuron fates. Genes \& Dev. 14: 2134 2139.

Sockanathan, S. and Jessell, T.M. 1998. Motor neuron-derived retinoid signaling specifies the subtype identity of spinal motor neurons. Cell 94: 503-514. 


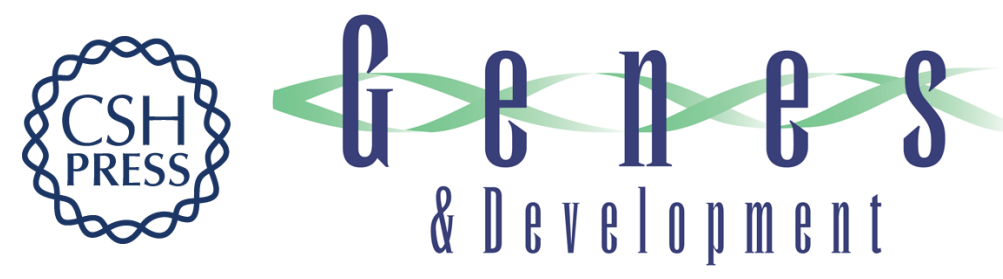

\section{Neural patterning: The role of Nkx genes in the ventral spinal cord}

Andrew P. McMahon

Genes Dev. 2000, 14:

Access the most recent version at doi:10.1101/gad.840800

References This article cites 21 articles, 7 of which can be accessed free at: http://genesdev.cshlp.org/content/14/18/2261.full.html\#ref-list-1

License

Email Alerting Receive free email alerts when new articles cite this article - sign up in the box at the top Service right corner of the article or click here.

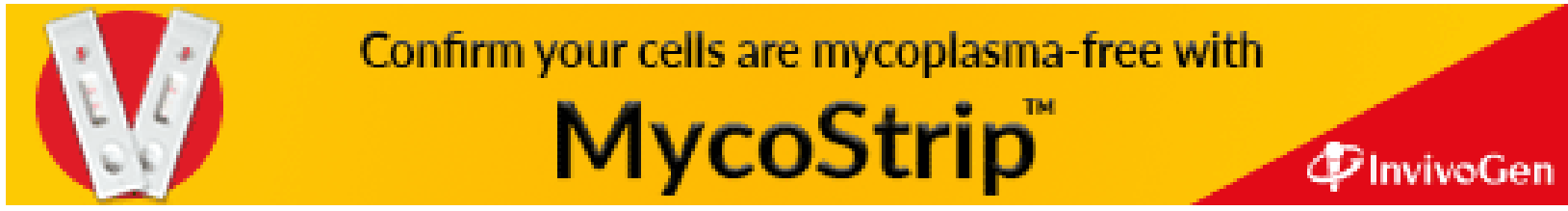

